\title{
LA CRISIS DEL CORONAVIRUS VISTA DESDE UN DIARIO DE DIFUSIÓN NACIONAL. EVOLUCIÓN ENERO-JUNIO DE 2020
}

\author{
The Coronavirus Crisis Seen from a National Journal. Evolutionary \\ Prospective from January-June 2020
}

\author{
Begoña CANTABRANA ${ }^{\mathrm{a}, \mathrm{b}, \mathrm{c}}$; Natalia COBIÁN ${ }^{\mathrm{d}}$; Claudio HIDALGO-CANTABRANA ${ }^{\text {; }}$ \\ Agustín HIDALGO
}

aÁrea de Farmacología, Departamento de Medicina, Universidad de Oviedo. 'Instituto Universitario de Oncología del Principado de Asturias. Instituto de Investigación Sanitaria de Asturias (España). 'Departamento de Alimentos, Bioprocesos y Nutrición, Universidad Estatal de Carolina del Norte (EE.UU.).

Correo electrónico: hidalgo@uniovi.es

Fecha de recepción: 10 de septiembre de 2020

Fecha de aceptación: 14 de septiembre de 2020

Fecha de publicación: 29 de enero de 2021

\begin{abstract}
Resumen
Los medios de comunicación son potencialmente útiles para la construcción social de acontecimientos de alto impacto, como es el caso de la actual crisis provocada por el coronavirus (SARS-CoV-2) y la enfermedad COVID-19. Para evaluar su impacto hemos analizado la edición impresa del diario El País entre los meses de enero y junio de 2020, identificando los textos periodísticos que aludían al virus o a la enfermedad, cuantificando su distribución en las páginas y las secciones del diario, las fuentes que se citan en los textos y la evolución de los géneros periodísticos a lo largo del periodo. El número más elevado de textos alusivos se registró en el mes de abril con 1872, con una media diaria de $64,6 \pm 9,6$. En este mismo mes, el número de páginas del diario en las que se alude a diferentes aspectos de la crisis supera el $70 \%$ del total. En la distribución por secciones, el mayor número de textos se alcanzó en Sociedad, seguidos de Economía, Opinión y España. Las noticias de ámbito nacional se mantienen a lo largo del periodo, mientras que las de ámbito internacional son elevadas al inicio de la crisis y luego descienden. Los géneros periodísticos de tipo
\end{abstract}




\title{
LA CRISIS DEL CORONAVIRUS VISTA DESDE UN DIARIO DE DIFUSIÓN NACIONAL. \\ EVOLUCIÓN ENERO-JUNIO DE 2020
}

BEGoÑA CANTABRANA; NATALIA COBIÁN; CLAUDIO HIDALGO-CANTABRANA; AGUSTÍN HIDALGO

\begin{abstract}
interpretativo son frecuentes al inicio, pero luego dominan los informativos; los considerados de opinión alcanzan su punto álgido en abril. La fuente documental más abundante es la institucional. Aunque los textos relacionados con salud son cuantitativamente poco numerosos en comparación con los temas económicos y políticos, se ha encontrado información relevante referida a salud pública, gestión sanitaria, asistencia sanitaria y medicamentos.
\end{abstract}

Palabras clave: prensa; coronavirus; COVID-19; textos periodísticos; diario El País.

\begin{abstract}
The media, and more specifically the print journalism, is a powerful source of information for the reconstruction of high impact social events, like the current crisis generated by the coronavirus (SARS-CoV-2) responsible for COVID-19 disease. To evaluate the impact, we analyzed the printed edition of the national journal El País, between January-June 2020, identifying the literature related to the virus or the disease. We quantified the different references and analyze the distribution across pages, sections of the journal, the sources of information and the organizations mentioned in the texts, together with the evolution overtime. The higher number of references (1872) was registered in April, with an average of $64.6 \pm 9.6$ per day. Also in April, the number of pages where a comment was related to the crisis represented the $70 \%$ of the total pages of the journal. By journal section, the higher number of references corresponded to Society, Economy, Opinion and Spain, in this particular order. The news related to national interest were continued overtime, whereas the international ones where higher at the beginning of the crisis with a decreasing tendency overtime. The journalism genres vary from mainly interpretative at the beginning, to informative later on, with opinion texts reaching their highest levels in April. The information source more frequently used in each text corresponds to institutional organizations. Noteworthy, even if the number of texts related with health is lower than those related to economy and politics, there have been a notorious number of information related to public safety, health management, health assistance and drugs.
\end{abstract}

Keywords: press; coronavirus; COVID-19; print journalism; journal El País.

\section{INTRODUCCIÓN}

El pasado siglo XX se ha caracterizado, entre otros cambios, por profundas transformaciones sociales y sanitarias generadas por el desarrollo de la ciencia y la tecnología. Una de ellas se produjo en el campo de la biología y de las ciencias de la vida con un considerable aumento de los conocimientos fundamentales y aplicados a la salud $^{1-3}$. Por otra parte, el interés por explicar al mundo lo que ocurría, así como el derecho del público a saber y participar en la toma de decisiones, convirtió a los medios de comunicación en un puente entre los centros de investigación y la población, creando secciones específicas para responder a un creciente interés por la apropiación del conocimiento científico ${ }^{4}$. Esto se ha traducido en la existencia de medios de alta divulgación científica, revistas de información general y diarios con informes periodísticos relacionados con la medicina, las ciencias y los medicamentos, entre otros temas ${ }^{5,6}$, con una calidad aceptable ${ }^{7-10}$. En líneas generales, la información de los medios de comunicación conjuga componentes humanos, políticos y económicos, lo que les confiere no sólo interés público sino también una dimensión sociológica que puede ser observada y analizada de forma científica ${ }^{11}$.

Los medios de comunicación tradicionales, como es la prensa escrita, se han concebido como un servicio de información e interpretación de la realidad, además de como una pieza clave en el control y vigilancia del poder ${ }^{12}$. Por ello, en el plano que nos ocupa, los medios 
son instrumentos que contribuyen no sólo a la formación de una cultura general crítica, sino también a la adquisición de una cultura científica y sanitaria ${ }^{13-15}$. De la misma forma, las diferentes modalidades que conforman estos medios pueden entenderse como fuentes documentales que permiten obtener información sobre acontecimientos incidentales en el ámbito de la salud y de la ciencia, y ayudar a construir los avances más significativos que han tenido lugar en los últimos años ${ }^{4}$.

Una de las principales funciones del periodismo de salud es la divulgación médica, entendida como un papel de mediación entre la ciudadanía y los profesionales sanitarios; otra, es la difusión de contenidos educativos con el fin de ayudar al público a conocer y controlar su estado de salud ${ }^{16}$. Estas funciones son importantes por cuanto los medios acceden a gran parte de la población, lo que les convierte en un elemento indispensable de la educación sanitaria. Además, la información que aparece en los medios de comunicación puede incidir en el comportamiento de los ciudadanos en relación a hábitos de vida saludables ${ }^{16}$. Pero también, es relevante el papel de los medios de comunicación para conocer la dimensión de los problemas (su extensión, intensidad con los que afecta a diferentes actividades humanas...), las medidas administrativas y sociales que se adoptan y el resultado de las mismas. Estas circunstancias o características alcanzan su punto álgido y son sometidas a máxima urgencia informativa cuando los acontecimientos se presentan de forma aguda, en forma de crisis, como es el caso de la actual pandemia por el SARS-CoV-2 y la enfermedad COVID-19. Por ello es importante el análisis de la comunicación que se ha realizado en los medios sobre este aspecto emergente.

El objetivo de este artículo es describir el alcance informativo de la enfermedad COVID-19 en España a través de las noticias incluidas en las diferentes secciones de un diario de difusión nacional.

\section{MATERIAL Y MÉTODOS}

Para la realización del estudio se ha utilizado la edición impresa del diario El País. Es, además, el diario de mayor tirada a nivel nacional en España, siendo su cifra de distribución de 91.727 ejemplares en la edición diaria y de 165.000 en los fines de semana de enero de 2020, aunque, como toda la prensa impresa pierde difusión por la competencia de la prensa digital. El diario está estructurado en varias secciones (Internacional, Opinión, España, Sociedad, Economía, etc.), a lo largo de las que hemos identificado la presencia de textos periodísticos sobre el coronavirus responsable de la pandemia COVID-19.

El periodo de observación ha sido el comprendido entre el 2 de enero y el 30 de junio de 2020. La recogida de información se ha realizado manualmente de los ejemplares de la edición impresa del diario. Se han considerado dos periodos: pre-confinamiento y confinamiento. En el primer caso, los datos comprendidos entre el 2 de enero y el 7 de marzo, día en el que la Organización Mundial de la Salud declaró el estado de pandemia y fue precursora de la declaración de estado de alarma en España, proceden de la colección CONPRE-Oviedo (2001-2020) ${ }^{4}$. En el segundo caso, para obtener la información correspondiente al período 8 de marzo a 30 de junio, los ejemplares del diario fueron revisados por dos personas de forma independiente quienes han analizado la relación de cada uno de los textos periodísticos con la COVID-19, seleccionando los que se consideraron vinculados. La descripción de los resultados, no obstante, se ha organizado teniendo en cuenta aspectos cuantitativos y cualitativos de la información recogida.

La información extraída de cada ejemplar ha sido la siguiente:

1. Número de páginas totales del diario; 2. Número de páginas de todas las secciones del 


\section{LA CRISIS DEL CORONAVIRUS VISTA DESDE UN DIARIO DE DIFUSIÓN NACIONAL. EVOLUCIÓN ENERO-JUNIO DE 2020}

BEGOÑA CANTABRANA; NATALIA COBIÁN; CLAUDIO HIDALGO-CANTABRANA; AGUSTÍN HIDALGO

diario bajo el cintillo "La crisis del coronavirus"; 3. Número de páginas en las que se han insertado textos relacionados con el coronavirus; 4. Número de noticias relacionadas con el coronavirus tanto en portada como en las diferentes secciones; 5 . Tipificación de las noticias según los géneros periodísticos; 6 . Género de los firmantes de los textos periodísticos; 7. Distribución de los textos periodísticos en las diferentes secciones del diario; 8. Ámbito nacional o internacional de los textos; 9. Fuentes que sustentan la información; 10. Presencia de iconografía; 11. Relación con aspectos de salud.

Para la tipificación de los géneros periodísticos se ha utilizado la siguiente clasificación ${ }^{17}$ : Textos Informativos (artículos que presentan un hecho de actualidad de forma documentada. Se han incluido las noticias y los reportajes y entrevistas objetivas), textos de opinión (artículos que recogen el planteamiento general de quien lo escribe sobre un tema con total libertad de expresión. Se han incluido editoriales, artículos de opinión, columnas y cartas al editor), y textos interpretativos (artículos que combinan la información con la opinión. Se han incluido las crónicas, las entrevistas y los reportajes interpretativos).

Para la distribución en secciones, se han considerado los textos incluidos en a) Portada y contraportada; b) Internacional; c) Opinión; d) España; e) Sociedad; f) Cultura; g) Deportes y e) Economía. Por otra parte, las fuentes de documentación se han clasificado en a) Institucionales (Gobierno, instituciones públicas, etc.); b) Profesional (profesionales sanitarios, asociaciones, colegios profesionales); c) Científicas (opinión de científicos, revistas científicas, sociedades científicas); d) Experto (opinión de expertos en una materia determinada); y e) Sociales (asociaciones de enfermos, colectivos sociales, sindicatos, ...). Por último, los aspectos relacionados con la salud se han tipificado según su relación con a) la salud pública: b) la gestión sanitaria; c) la asistencia sanitaria y d) por su alusión a medicamentos.

La información obtenida se incorporó a una base de datos diseñada para ello utilizando el software Microsoft Office Excel 2016 con el que se ha realizado la distribución de frecuencias. Los datos en los resultados se muestran como porcentajes, media \pm desviación, y la moda en valores absolutos.

\section{REsUltados}

\section{El comienzo del relato}

Los medios de comunicación, el diario El País entre ellos, empiezan a hacerse eco del problema a lo largo del mes de enero. Mientras se sigue la evolución en la ciudad de Wuhan con once millones de habitantes cerrada a cal y canto, se va conociendo que el nuevo virus se contagia entre humanos, se va extendiendo a otros países y salta a Europa con los primeros dos casos diagnosticados en Francia el 24 de enero. La epidemia alcanza la primera página del diario El País el día 21 de enero con el siguiente titular:

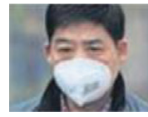

salud Las claves del virus letal que se expande por Asia

A final de mes, se informa de 10 casos en Europa, 1 de ellos en Finlandia, 4 en Alemania y 5 en Francia. El confinamiento de la ciudad de Wuhan provoca que algunos españoles queden "atrapados" y se plantee su repatriación, algo que ya ha sido noticia de prensa con motivo de anteriores epidemias, en este caso pasarán cuarentena en el hospital Gómez Ulla de Madrid, lo que inician el día 1 de febrero. También surgen de forma precoz metáforas (como la que sugiere que "Ias bolsas se contagian del miedo al coronavirus"), e informaciones como la identificación del primer supercontagiador, la amenaza a la economía china, al transporte, al turismo, etc. que van confeccionando un escenario de 


\section{LA CRISIS DEL CORONAVIRUS VISTA DESDE UN DIARIO DE DIFUSIÓN NACIONAL. EVOLUCIÓN ENERO-JUNIO DE 2020 \\ BEGOÑA CANTABRANA; NATALIA COBIÁN; CLAUDIO HIDALGO-CANTABRANA; AGUSTÍN HIDALGO}

tragedia mundial que ha pasado por muchos hitos, algunos de los cuales se incluyen en la tabla 1.

El 30 de enero, ya se incorpora el cintillo denominado La Crisis del Coronavirus en la cabecera de las páginas que incluyen la información sobre la enfermedad. Inicialmente, este cintillo se incluye en la sección de Sociedad, pero posteriormente se extendió al resto de las secciones del diario.

Si bien hasta el 22 de febrero la epidemia en Europa se centra en Italia, comienzan a surgir

Tabla 1. Algunos hitos relevantes en la crisis del coronavirus y la enfermedad COVID-19 entre el 31 de diciembre de 2019 y el 30 de junio de 2020

\begin{tabular}{|c|c|}
\hline Fecha & Hechos \\
\hline 31 de diciembre & $\begin{array}{l}\text { El Gobierno de China comunica a la OMS } 27 \text { casos de neumonía de origen desconocido con } \\
\text { posible origen en la ciudad de Wuhan. }\end{array}$ \\
\hline 4 de enero & $\begin{array}{l}\text { La OMS informa en redes sociales de un conglomerado de casos de neumonía en la ciudad } \\
\text { china de Wuhan. }\end{array}$ \\
\hline 7 de enero & Se identifica como agente causal a un nuevo coronavirus (2019-nCoV-2). \\
\hline 9 de enero & Primer muerto por el nuevo coronavirus. \\
\hline 12 de enero & China hace pública la secuencia genética de los virus responsables. \\
\hline 13 de enero & Se comunica el primer caso diagnosticado fuera de China (Tailandia). \\
\hline 21 de enero & EEUU notifica el primer caso confirmado fuera de Asia. \\
\hline 22 de enero & Se confirma la transmisión entre seres humanos en China. \\
\hline 23 de enero & $\begin{array}{l}\text { Las autoridades chinas declaran la cuarentena en Wuhan, cierran la ciudad, cancelan aviones, } \\
\text { trenes y transporte interior, y aísla a } 21 \text { millones de personas para frenar la expansión del } \\
\text { virus. }\end{array}$ \\
\hline 30 de enero & $\begin{array}{l}\text { La OMS declara que el brote constituye una Emergencia de Salud Pública de Importancia } \\
\text { Internacional (ESPII). }\end{array}$ \\
\hline 31 de enero & Hay 17 países con casos confirmados, 7826 afectados y y 170 muertos (sólo 10 en Europa). \\
\hline 1 de febrero & $\begin{array}{l}\text { El Gobierno italiano declara el estado de emergencia por el coronavirus. } \\
\text { Varios países recomiendan no viajar a China. } \\
\text { Se detectan los primeros contagios de pacientes asintomáticos en Alemania. } \\
\text { España considera que las medidas recomendadas por la OMS ya se aplican. }\end{array}$ \\
\hline 2 de febrero & $\begin{array}{l}\text { El primer caso de afectado en España se registra en La Gomera; se trata de un ciudadano } \\
\text { alemán que lo contrajo en su país. }\end{array}$ \\
\hline 13 de febrero & Primer muerto por COVID-19 en España: un hombre de 69 años en Valencia. \\
\hline 19 de febrero & $\begin{array}{l}\text { El Director General de la OMS culpa a la infodemia de propagar pánico y confusión y de } \\
\text { obstaculizar las medidas de contención del brote. }\end{array}$ \\
\hline 22 de febrero & $\begin{array}{l}\text { Italia aísla } 10 \text { pueblos en la región de Lombardía y Veneto, y se suspende el carnaval de } \\
\text { Venecia. }\end{array}$ \\
\hline 27 de febrero & España registra el primer caso de contagio local del virus. \\
\hline 29 de febrero & La OMS eleva a muy alto el riesgo de impacto global del coronavirus. \\
\hline
\end{tabular}

Rev. Med. Cine. 2020; 16 (e), 137-154 Ediciones Universidad de Salamanca / 
LA CRISIS DEL CORONAVIRUS VISTA DESDE UN DIARIO DE DIFUSIÓN NACIONAL.

EVOLUCIÓN ENERO-JUNIO DE 2020

BEGOÑA CANTABRANA; NATALIA COBIÁN; CLAUDIO HIDALGO-CANTABRANA; AGUSTÍN HIDALGO

\begin{tabular}{|l|l|}
\hline Fecha & Hechos \\
\hline 5 de marzo & $\begin{array}{l}\text { Segundo fallecido en España: un hombre de } 86 \text { años en Bilbao. Serían el grupo más afectado } \\
\text { durante la pandemia. }\end{array}$ \\
\hline 11 de marzo & $\begin{array}{l}\text { La OMS declara la pandemia por COVID-19. Curiosamente, el mismo día, el presidente chino } \\
\text { Xi Jin Ping, da por ganada la batalla contra el virus. }\end{array}$ \\
\hline 19 de marzo & $\begin{array}{l}\text { El Gobierno español decreta el estado de alarma y el confinamiento desde el sábado } 14 \text { de } \\
\text { marzo }\end{array}$ \\
\hline 20 de marzo & $\begin{array}{l}\text { China y EEUU anuncian el comienzo de los ensayos para una vacuna } \\
\text { China vive su primer día sin nuevos positivos. }\end{array}$ \\
\hline 25 de marzo & La India ordena el confinamiento de 1.300 millones de personas. \\
\hline 2 de abril & España acumula 10.000 muertos, 900.000 empleos destruidos y 3 millones en ERTE. \\
\hline 7 de abril & China registra el primer día sin muertos por coronavirus desde enero. \\
\hline 30 de abril & China da por vencida la crisis. \\
\hline 11 de mayo & España inicia la desescalada. \\
\hline 21 de mayo & EEUU comunica a la OMS que abandona la organización. \\
\hline 27 de mayo & EEUU alcanza los 100.000 muertos. \\
\hline 29 de mayo & $\begin{array}{l}\text { El Gobierno aprueba la Renta Mínima Vital. } \\
\text { Más de } 100 \text { expertos alertan de fallos en el mayor estudio sobre cloroquina. }\end{array}$ \\
\hline 21 de junio & España completa la desescalada. Es la hora de la responsabilidad ciudadana. \\
\hline
\end{tabular}

noticias indicativas de los preparativos para cuando llegue la epidemia a España. Se publican recomendaciones con indicaciones de uso de mascarilla, de higiene corporal, de taparse al estornudar, sobre cuáles son los síntomas sospechosos de padecer la enfermedad y de cuándo acudir al médico. También se nos informa de que "Los hospitales ultiman planes de contingencia y revisan los protocolos en España"18 y de que "El laboratorio de coronavirus del CSIC trabaja con centros de EEUU para desarrollar una vacuna". Por si acaso, los ciudadanos hacen acopios de mascarillas, cuya demanda, según fuentes farmacéuticas, aumenta un $8000 \%$ provocando el desabastecimiento. Pero por seguir con la tradición, una vez más, los Estados de la Unión Europea son incapaces de acordar un criterio común para definir los casos sospechosos en una reunión celebrada el 25 de febrero, lo que supone que cada Estado utilice "sus" criterios y provoque un irritante baile de números de afectados y muertos más propios de estrategias políticas que de responsabilidad sanitaria. Ese mismo día, 25 de febrero, el diario se hace eco de que la UE insta a los Estados miembros a que no cierren las fronteras.

Y en medio de todo ello, la desinformación y los bulos sobre los que el Director General de la OMS, Tedros A. Ghebreyesus, y Alex Ng advierten en un artículo y culpan a la Infodemia de obstaculizar las medidas de contención del brote y propagar pánico y confusión de forma innecesaria.

\section{La enfermedad en España}

El día 1 de marzo se reconoce un foco preocupante en Torrejón de Ardoz (Madrid) generado 
a partir de personas que proceden de Ecuador, preocupación que va en aumento en los días siguientes y lleva a Madrid a abanderar el número de afectados desde el día 3 . El día 2 se anuncia el contagio del escritor Luís Sepúlveda (posiblemente contagiado en Lisboa), el primer personaje mediático afectado. También en los primeros días de marzo se comunican los primeros positivos en el personal sanitario que llegó a ser muy preocupante; se conoce que el virus es más contagioso y mortal que la gripe y, a pesar de las recomendaciones de la UE, algunas compañías comienzan a suspender vuelos mientras continúa la repatriación de afectados.

Por otra parte, el análisis de los primeros fallecidos sugiere que el virus llevaba al menos cuatro semanas circulando en España, según informa Oriol Güell que pone en boca del epidemiólogo Antoni Trilla "Estas muertes apuntan a que el virus llegó antes de lo pensado". El propio día 5 de marzo, la OMS llama la atención sobre el siguiente hecho: "Nos preocupa que algunos países no estén tomándose el problema suficientemente en serio o que hayan decidido que no pueden hacer nada. Hay que llevar esto al máximo nivel".

En el terreno deportivo se recomienda que los partidos de futbol Valencia-Atalanta y Getafe-Inter, se celebren sin público. Este hecho inicia un parón competitivo que se prolongó hasta finales de junio en que se reanudó la competición de la liga de futbol.

Se conoce el primer gran foco generado por la asistencia a un funeral en Vitoria que genera la instauración de una cuarentena vigilada en Haro (La Rioja), la Guardia Civil pasa a ocupar el primer término del control de la movilidad y las empresas empiezan a ensayar el teletrabajo que se convertirá en casi universal durante el posterior confinamiento. El día 10 de marzo, ya hay más de millón y medio de escolares sin clase y España supera los 1000 contagios diarios, los mercados entran en pánico, los inversores huyen de las bolsas y aumentan las primas de riesgo de Italia y España. Empiezan a escucharse voces que reclaman que Europa debe prepararse para ayudar a los países más vulnerables económicamente.

Los aspectos lúdicos se van cancelando independientemente de su repercusión económica y, al tiempo que se resalta que las UCl se preparan para afrontar el peor escenario, se imponen "cordones sanitarios" en los países y aumenta el control de acceso de viajeros en todo el mundo. En medio de todo esto, Marciano Sánchez Bayle, presidente de la Asociación para la Defensa de la Sanidad Pública resalta en su artículo de opinión que "La prudencia y la buena información resultan fundamentales, pero también conocer los objetivos ${ }^{\prime \prime 1}$, algo poco claro dentro del caos y el pánico inicial. Un ejemplo de la situación de pánico entre la población es la imagen de las grandes superficies comerciales "arrasadas" por la demanda de los ciudadanos que hacen acopio de productos para largo tiempo. La situación se mantiene durante días a pesar de que se reitera que el abastecimiento está asegurado. Pero, como indicó Juan Roig, propietario de la cadena de supermercados Mercadona "Si algo agrava la situación es el miedo"

El día 14 de marzo, Europa ya es el epicentro de la pandemia, España acumula 142 muertos por coronavirus y amanece confinada. Las noticias indican que las $\mathrm{UCl}$ no están totalmente preparadas y se duda de que sean suficientes. Se avecina una crisis social inmensa que requerirá espacios para alojar a migrantes e indigentes y nos vuelven locos con cursos acelerados sobre los tipos y bondades de mascarillas. El día 15 todos los diarios impresos llevan una sobrecubierta con el lema "Este virus lo paramos entre todos". El interior muestra imágenes de calles y avenidas desiertas. Empiezan a surgir dudas sobre los métodos de estimación de las tasas de afectados y de letalidad en mayores y algunas Comunidades Autónomas, ante la precariedad de medios, 


\section{LA CRISIS DEL CORONAVIRUS VISTA DESDE UN DIARIO DE DIFUSIÓN NACIONAL. \\ EVOLUCIÓN ENERO-JUNIO DE 2020}

BEGoÑA CANTABRANA; NATALIA COBIÁN; CLAUDIO HIDALGO-CANTABRANA; AGUSTÍN HIDALGO

dejan de realizar test en los casos leves. Las personas mayores se sienten "Aislados, solos y con miedo" según un artículo de Manuel Jabois.

El 25 de marzo, el diario atribuye en portada a la presidenta de la Unión Europea la afirmación "Acabamos de cerrar la compra del material sanitario que necesita la UE" y, en tipo de letra más reducido, que "La dirigente comunitaria aplaude la idea de Sánchez de un Plan Marshall". Ambos asuntos han sido, junto a los afectados y muertos, los platos fuertes de un largo período de confinamiento en el que la colaboración ciudadana ha sido la norma.

De forma temprana se observa que los más afectados son los ancianos; es un efecto edad dependiente pero los varones acumulan el doble de la mortalidad. Se agrava el problema en las residencias y se pone en compromiso la Atención Primaria por las bajas de personal afectado y la falta de material.

Las críticas de los profesionales a la gestión política y la falta de recursos provocan la dimisión de la Consejera de Sanidad de Aragón, de la Directora General de Salud Pública de la Comunidad de Madrid, la destitución de una Jefa de Servicio en Galicia y tiranteces en la Comunidad Valenciana.

Bajo el rótulo "El País se queda en casa", cada día desde que se decretó el confinamiento, algunos autores y críticos sugieren películas, discos, libros, series, cómic y videojuegos para ayudar a hacer más llevadero el encierro. También se incrementa la oferta de cultura gratuita en la red. Los medios no se olvidan de resaltar la labor de los trabajadores que desafían al virus: empleados de supermercados, transporte, reparto domiciliario, panaderías, agricultores, etc.

Mientras, Elena G. Sevillano se hace eco de la polémica por el contaje de los muertos y los afectados, y escribe un artículo titulado "Cada país cuenta los muertos a su manera y ninguno lo hace bien"20. María Neira, por su parte, a la pregunta de si ¿El coronavirus es lo peor que nos ha pasado en la vida?, responde que "Es lo más excepcional en todo el sentido de la palabra. Por la situación global, por la atención, por el pánico que ha generado, por lo que se ha pedido al mundo. Nunca en salud pública se había pedido a nadie quedarse en casa, y hoy tenemos a un tercio de la población del planeta confinada y parando la actividad económica. Nunca pensé que iba a pasar".

Entretanto, la picaresca sigue su curso (" $\mathrm{La}$ fiscalía alerta de fraudulentas adopciones de perros "para salir a la calle"), la afectación del personal sanitario se incrementa dolorosamente (el día 26 de marzo se conoce que ya son dos médicos los fallecidos y 5.400 los contagiados), la economía empieza a deteriorarse y ya el día 30 se indica, después del enfado empresarial por el parón del trabajo, que éste puede costar 49.000 millones en un mes.

A partir de este momento, el confinamiento y el encono político cambian la convivencia de los ciudadanos por un tiempo aún indeterminado.

\section{Aspectos cuantitativos}

Durante los meses de enero y febrero, el número de noticias recuperables de la colección CONPRE-Oviedo es muy limitado y están contenidas fundamentalmente en la sección de Sociedad. A partir de marzo, el número de textos aumenta de forma creciente alcanzando el máximo durante el mes de abril con 1872 textos periodísticos que decrecen posteriormente hasta los 732 textos en junio. Cuando analizamos la media de noticias diarias, obtenemos $5,6 \pm 3$, 4 en febrero con un máximo de $64,6 \pm 9,6$ en abril y un descenso posterior hasta las $24,4 \pm 7,5$ en junio (Figura 1).

La información durante enero y febrero está, en buena medida, sustentada en noticias de COVID-19 con origen en China, en el confinamiento de una ciudad entera de once millones de habitantes, en los controles extremos llevados a 


\section{LA CRISIS DEL CORONAVIRUS VISTA DESDE UN DIARIO DE DIFUSIÓN NACIONAL. EVOLUCIÓN ENERO-JUNIO DE 2020}

cabo por la policía y el ejército, en la construcción de un hospital en tiempo record, y en la restricción en el acceso a las instalaciones educativas y al ámbito laboral a las que los ciudadanos se incorporan lentamente.

A comienzos de febrero ya hay noticias de prensa que resaltan que la expansión de la infección está poniendo a prueba la capacidad de respuesta mundial y que diferentes laboratorios académicos y de la industria farmacéutica han iniciado el desarrollo de vacunas. También hay noticias de que la nueva enfermedad está forzando a la ciencia a compartir estudios y de un acuerdo sin precedentes de más de 70 organizaciones (entre ellas las publicaciones más relevantes como Nature, Cell, Lancet o los institutos de salud de EEUU) para publicar en abierto las investigaciones sobre la COVID-1921. El día 10 ya se contabilizan 43.000 afectados, 1000 muertos por coronavirus y el día 12 de febrero el diario indica que La OMS declara al coronavirus, en boca de su director, "enemigo público número uno de la humanidad".

Los hechos precedentes tienen, en buena lógica, repercusión en la cantidad de noticias que genera el coronavirus, lo que permite poner de manifiesto que en el mes de marzo el porcentaje de páginas del diario que dedica algún artículo al coronavirus es superior al $50 \%$, aproximándose al $75 \%$ en el mes de abril, para luego reducirse

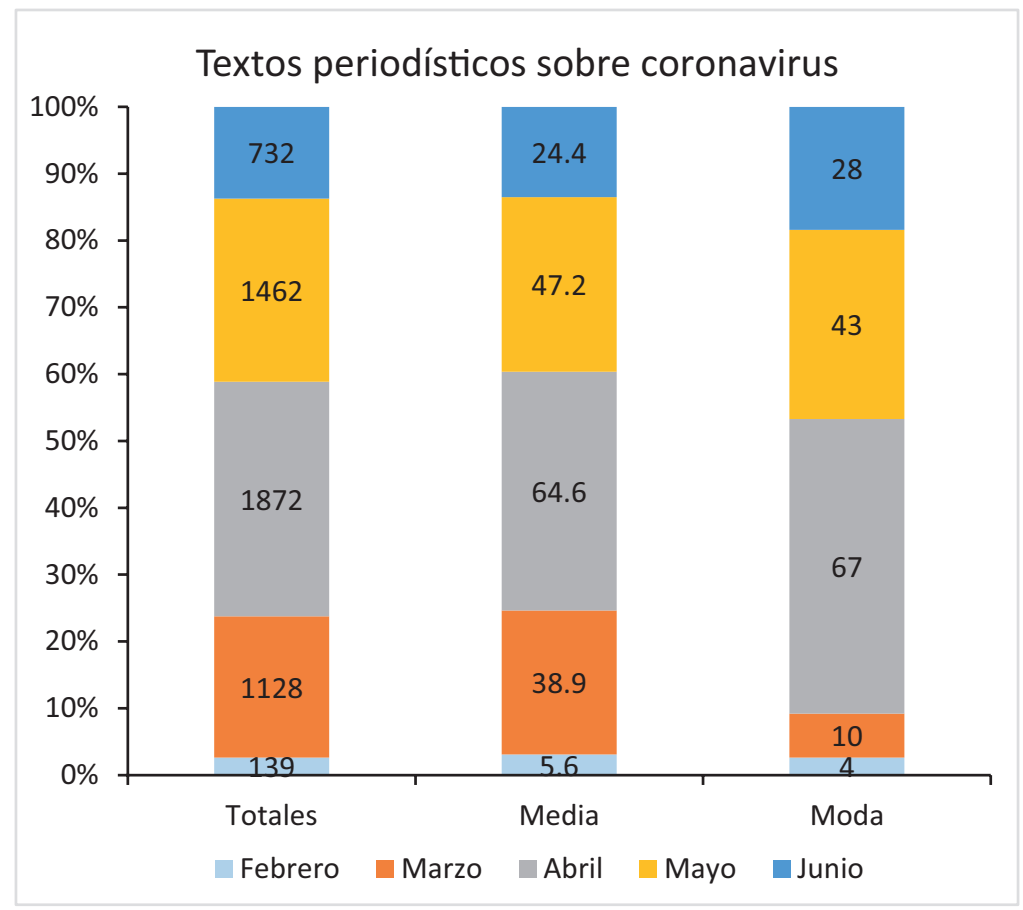

Figura 1. Distribución del número acumulado de textos periodísticos relacionados con la infección por coronavirus (SARS-CoV-2) y la enfermedad COVID-19 publicados en el diario El País durante los meses de febrero a junio de 2020. Se muestran los valores totales, el porcentaje mensual de textos, y la moda. 


\section{LA CRISIS DEL CORONAVIRUS VISTA DESDE UN DIARIO DE DIFUSIÓN NACIONAL. EVOLUCIÓN ENERO-JUNIO DE 2020}

BEGOÑA CANTABRANA; NATALIA COBIÁN; CLAUDIO HIDALGO-CANTABRANA; AGUSTÍN HIDALGO

gradualmente (Figura 2). Algo similar ocurre con las páginas impresas que contienen el cintillo $L a$ Crisis del Coronavirus: superior al $45 \%$ en el mes de marzo y al $60 \%$ en el mes de abril. (Figura 2 ) La disparidad de datos entre el número de páginas que contienen textos periodísticos sobre el coronavirus y el de páginas bajo el cintillo de La Crisis del Coronavirus se debe a que hay páginas más allá de las incluidas bajo el rótulo que dedican artículos al coronavirus, como es el caso de las cuatro páginas de la sección de Opinión que se incluyen a diario.

Como muestra la Figura 3, a lo largo del periodo de estudio ha sido posible identificar artículos periodísticos en todas las secciones del diario. En "Portada" y "Contraportada" se produjo un incremento paulatino, estabilizando en mayo y junio. En el caso de las noticias de la sección "Internacional", se alcanza el máximo en marzo y luego desciende, posiblemente porque la atención mediática se mueve del ámbito internacional al nacional (Figura 3). Las noticias de la sección "España", llegan a alcanzar un $20 \%$ de todas las noticias sobre la pandemia, cifras que son ampliamente superadas por las que se identificaron en las secciones de "Economía", y "Sociedad". Un aspecto importante es la cantidad de textos periodísticos que se incluyen en la sección de "Opinión" que alcanza otro 20 \%. En esta sección se incluyen tanto los editoriales como los artículos de opinión y las cartas al editor relacionados con la pandemia que, durante los períodos de abril a junio, han sido protagonistas.

La Figura 4 muestra que las noticias de ámbito nacional tuvieron un pico en el mes de marzo y luego se produjo un discreto descenso (pero manteniéndose alrededor del $40 \%$ ), y un ascenso posterior durante mayo y junio. En cambio, las noticias de ámbito internacional tuvieron un protagonismo importante al comienzo de la pandemia condicionado por las crónicas de corresponsales y enviados especiales al lugar de origen y a los lugares por donde se iba extendiendo la infección.

Los géneros periodísticos utilizados han ido variando a lo largo de los meses. Los informativos han alcanzado el máximo número de textos en el mes de junio, superando el $45 \%$ de los textos

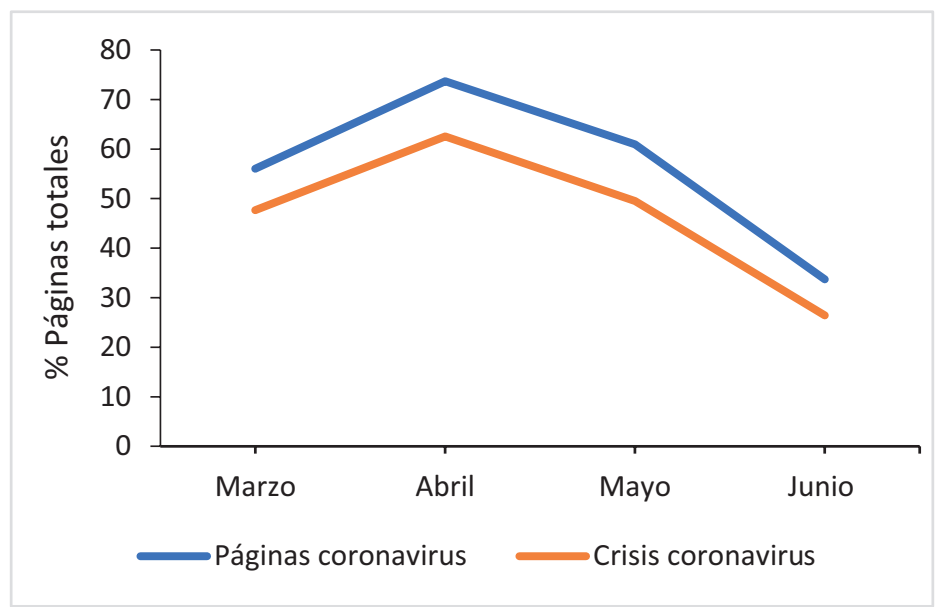

Figura 2. Evolución del porcentaje de páginas editadas por el diario El País (edición impresa) bajo el cintillo La Crisis del Coronavirus (Crisis coronavirus), y del porcentaje de páginas totales en las que se incluyen textos periodísticos sobre el coronavirus (Páginas coronavirus). 


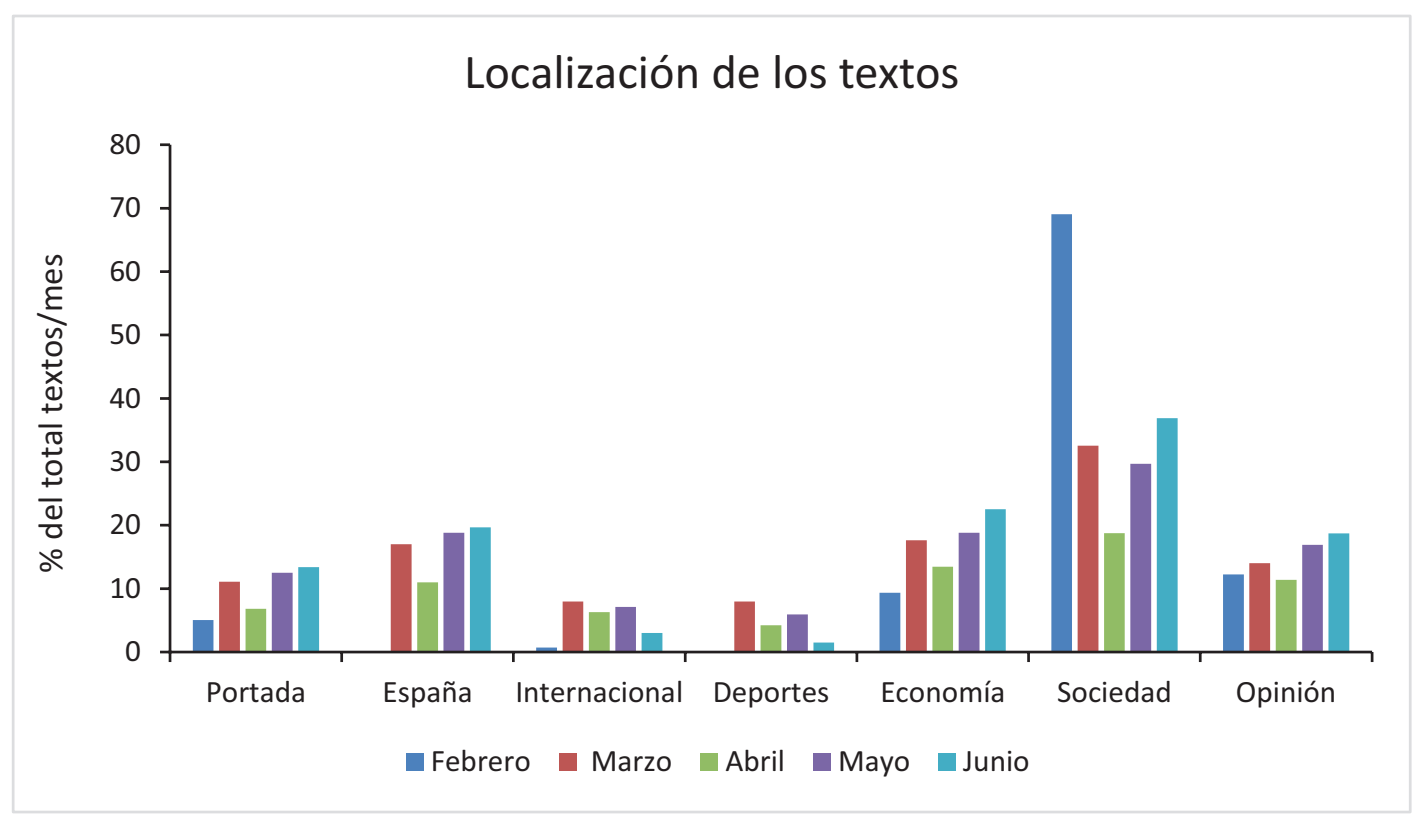

Figura 3. Distribución de los textos periodísticos relacionados con el coronavirus y la COVID-19 publicados en las diferentes secciones del diario El País durante el periodo febrero a junio de 2020.

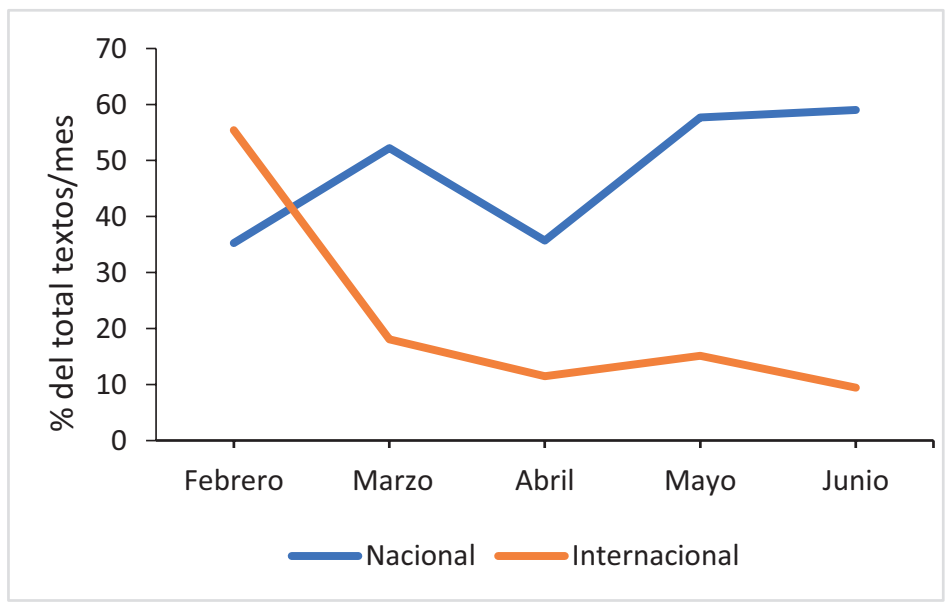

Figura 4. Evolución de los textos periodísticos sobre coronavirus y COVID-19, de ámbito nacional e internacional, publicados en el diario El País durante el periodo febrero a junio de 2020.

periodísticos relacionados con la crisis del coronavirus. En cambio, los interpretativos fueron claramente altos durante los meses de febrero y marzo respecto a los del periodo abril-junio. En el mes con más textos se superaron el $50 \%$ de los relacionados con el coronavirus. En cambio, 


\section{LA CRISIS DEL CORONAVIRUS VISTA DESDE UN DIARIO DE DIFUSIÓN NACIONAL. EVOLUCIÓN ENERO-JUNIO DE 2020}

los textos propios del género de opinión alcanzan el máximo durante el mes de abril en el que llegan al $30 \%$ de los textos periodísticos recogidos (Figura 5).

Dentro de las noticias relacionadas con salud, el diario ha dedicado atención a las relacionadas con salud pública, gestión sanitaria, atención sanitaria y medicamentos (Figura 6). Cuantitativamente el número de textos no ha sido muy elevado, pero se han relacionado con aspectos esenciales tales como:

a) actualización de las cifras de afectados y fallecidos con su distribución por Comunidades Autónomas;

b) la difusión e interpretación de las medidas adoptadas por el gobierno para la prevención y tratamiento de la enfermedad;

c) la evolución del conocimiento sobre la enfermedad;

d) la evolución del resultado de los tratamientos;

e) la repercusión de las medidas administrativas en la evolución de la afectación en las residencias de ancianos; f) la necesidad y evaluación de instalaciones complementarias para atender a los enfermos de COVID-19;

g) las explicaciones pormenorizadas de los instrumentos de uso ciudadano para la prevención de los contagios, tales como geles y mascarillas, e información de las razones que sustentan mantener la distancia de seguridad;

h) la información sobre medicamentos ha girado en torno al potencial desarrollo de vacunas y a la significación de algunos medicamentos que han aportado mejoría a los enfermos, y al comentario de algún ensayo clínico o noticias relacionadas con alguno de ellos.

Las fuentes en la que los autores han cimentado la información han sido fundamentalmente institucionales, que han sido aludidas hasta en un $60 \%$ de los textos. Menor importancia ha tenido la opinión de expertos que sólo supero el $10 \%$ en el mes de marzo. En este mismo mes, en más del $10 \%$ de los textos citaron como fuente documental a profesionales sanitarios y algunas fuentes sociales. La alusión a fuentes cientificas ocupó el último lugar (Figura 7).

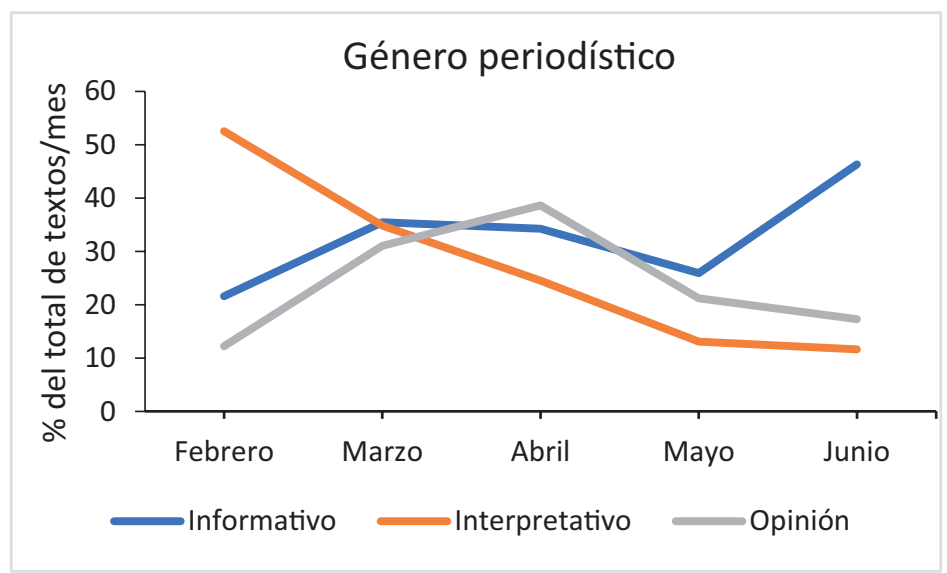

Figura 5. Curso temporal de los textos periodísticos sobre coronavirus y COVID-19, agrupados según género periodístico, publicados en el diario El País durante el periodo febrero a junio de 2020. 
LA CRISIS DEL CORONAVIRUS VISTA DESDE UN DIARIO DE DIFUSIÓN NACIONAL.

EVOLUCIÓN ENERO-JUNIO DE 2020

BEGOÑA CANTABRANA; NATALIA COBIÁN; CLAUDIO HIDALGO-CANTABRANA; AGUSTÍN HIDALGO

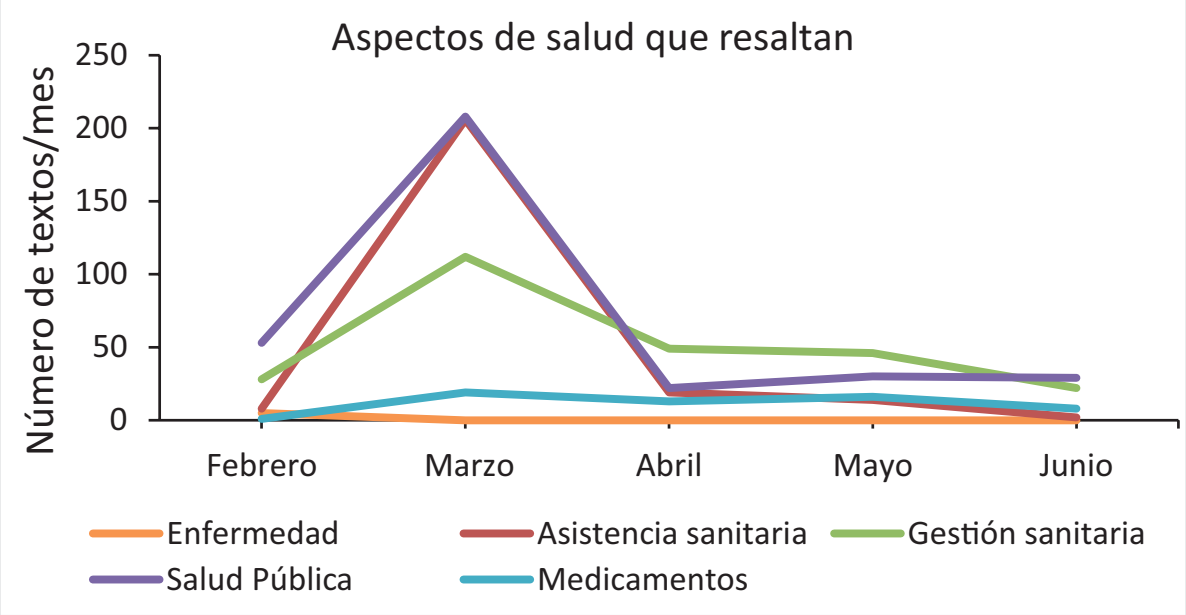

Figura 6. Número de textos periodísticos publicados por mes que resaltan los aspectos de salud indicados.

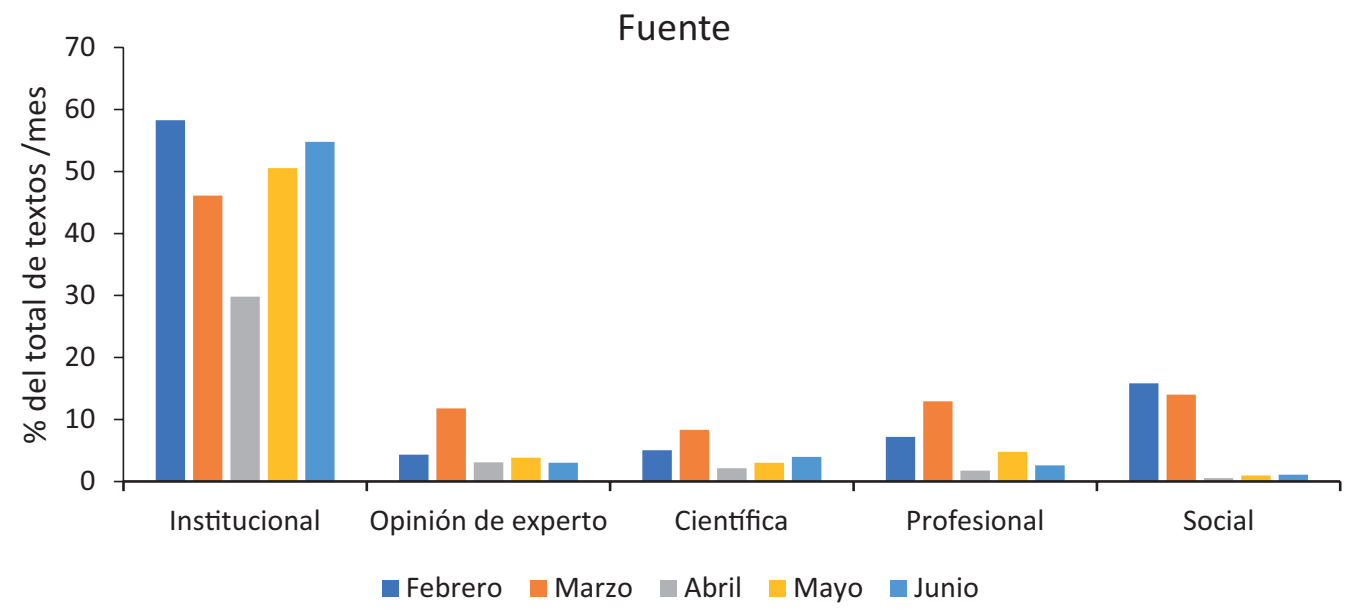

Figura 7. Distribución de las fuentes documentales identificadas en los textos periodísticos sobre coronavirus y COVID-19 publicados en el diario El País durante el periodo febrero a junio de 2020.

Por último, en el periodo febrero-mayo, ha sido mayoritario el número de textos firmados por hombres que el de mujeres. La proporción puede estimarse globalmente en $2 / 3$ de artículos firmados por hombres y $1 / 3$ firmado por mujeres. El número de autores que firmó artículos relacionados con el coronavirus alcanzó el máximo en el mes de abril con una media de 24,5 autores 


\section{LA CRISIS DEL CORONAVIRUS VISTA DESDE UN DIARIO DE DIFUSIÓN NACIONAL. EVOLUCIÓN ENERO-JUNIO DE 2020}

BEGoÑA CANTABRANA; NATALIA COBIÁN; CLAUDIO HIDALGO-CANTABRANA; AGUSTÍN HIDALGO

por día. Se da la circunstancia de que el número de autoras disminuye a medida que aumenta la duración de la pandemia lo que posiblemente se debe a la migración del foco informativo dado que las crónicas iniciales son escritas por mujeres en los lugares de origen de la misma y la relevancia informativa de Wuhan y China va declinando a medida que se extiende la pandemia (Figura 8).

La mayoría de los titulares de los textos periodísticos son asertivos o neutros, lejos de transmitir información sensacionalista y que genere alarma añadida a la gravedad de los hechos que contiene el texto narrativo. Con frecuencia, transmiten tranquilidad a pesar de la situación de crisis y procuran difundir opiniones de expertos que corroboren o no la información oficial.

Tamaño de la noticia. A medida que ha ido avanzando la cronología de la pandemia, los textos han ido ganando en extensión con reportajes y crónicas que ocupan una página entera y, en ocasiones, más de dos. Se excluyen, naturalmente, de esta situación las secciones y columnas fijas de opinión y cartas al editor que han mantenido la misma extensión habitual (cuatro páginas), incluyendo las cartas al editor y la viñeta editorial, de la sección de opinión.

Infografía. Los artículos han estado ilustrados con una importante y abundante infografía, dentro de la que han dominado las fotografías de personajes y de situaciones con función tanto de ilustrar la información como de ejemplificar lo que estaba ocurriendo y su alcance. También ha sido significativa la presencia de mapas que reflejaban la incidencia de la enfermedad en diferentes países, de gráficos de la evolución de las cifras de contagiados y muertos, esquemas de la extensión de la infección, sobre cómo se produce la incorporación del virus al interior del organismo, de las estructuras afectadas, así como sobre el potencial desarrollo de vacunas.

\section{DISCUSIÓN}

En enero, la Unión Europea está centrada en la construcción de una Europa verde que el diario El País resalta en titulares como "La UE prevé destinar un billón de euros para el clima". En España, el día 8 de ese mismo mes se constituye

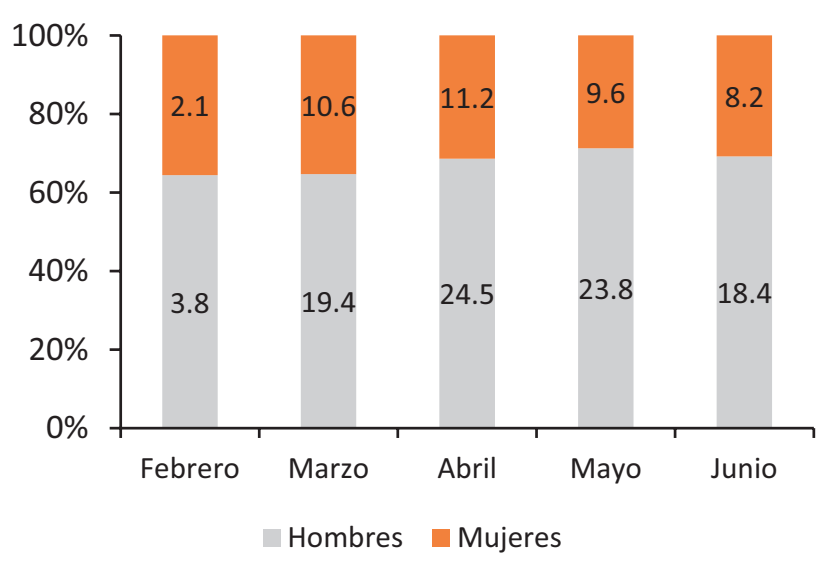

Figura 8. Distribución según el sexo de los autores de los textos periodísticos sobre coronavirus y COVID-19 publicados en el diario El País durante el periodo febrero a junio de 2020. (Los números dentro de las columnas refieren la media diaria de autores mujeres y hombres). 
el actual Gobierno de Coalición que incluye una "vicepresidencia verde" con Teresa Ribera en el Ministerio de Transición Ecológica. Y Barcelona declara la "Emergencia climática para reducir el $\mathrm{CO}_{2}$ ". Estando en esto, y en una sociedad ensimismada entregada a un capitalismo cada vez más salvaje, anidado en un mundo que Fernando Vallespín ${ }^{22}$ considera que "Navega huérfano de utopías", una nueva pandemia, generada por un virus, hace zozobrar la organización social y la relación del hombre con su entorno. Los historiadores y periodistas tienen ante sí la tarea de contarlo.

La irrupción de la pandemia ha generado una avalancha de información difícil de gestionar, aunque los medios no han dejado de intentarlo. Prácticamente todos los medios de comunicación han dedicado un sobre esfuerzo a la tarea, las editoriales se han sumado al mismo aportando reflexiones más o menos apresuradas sobre la situación, las revistas científicas relacionadas con la salud han publicado en acceso abierto prácticamente todo lo que les ha llegado relacionado con el coronavirus y la enfermedad COVID19 , las revistas científicas relacionadas con la comunicación han dado prioridad a los artículos relacionados con la pandemia. Ni que decir tiene que los medios que operan en internet han encontrado un terreno abonado para disparar su actividad y visibilidad, no siempre para contribuir a facilitar el control de la enfermedad. De hecho, ha sido posible detectar que los medios digitales ya trataban de forma tan precoz como el 9 de enero el tema que luego sería la pandemia ${ }^{23}$, y se incrementó de forma clara a partir de la promulgación del decreto del estado de alarma. A modo de ejemplo, Lázaro-Rodríguez y Herrera-Viedma ${ }^{23}$ encontraron en su estudio que entre el 14 y el 19 de marzo se publicaron 45.294 noticias en medios digitales, el triple de las publicadas a comienzos de mes.

A un nivel mucho más modesto, nuestros resultados detectan cómo los textos periodísticos relacionados con el coronavirus han tenido un incremento importante con el paso de los meses y la evolución de la pandemia, con el punto álgido en el mes de abril coincidiendo con el confinamiento y con una caída mantenida desde el "aplanamiento" de la curva de contagios. Esto confirma que en la información sobre la enfermedad COVID-19 se ha producido un patrón agudo de textos periodísticos ${ }^{4,5,24}$ condicionado por la irrupción brusca de la enfermedad en Europa y en España.

La media de noticias diarias ha sido muy elevada $(64,6 \pm 9,6$ en abril), llegando a estar presente en el $70 \%$ de las páginas del diario, lo que sugiere que ha afectado a todos los ámbitos informativos del mismo.

Como se ha descrito en otros estudios ${ }^{5,16}$ la mayoría de las informaciones sobre la pandemia se han incluido en Sociedad, una sección heterogénea pero la más visitada del diario, para la que se reservan temas de potencial interés social. También son destacables los porcentajes de textos incluidos en las secciones de Economía y Opinión, con constantes llamadas en portada. En la sección de España se han incluido, preferentemente, aspectos políticos relacionados con la gestión de la pandemia. Los géneros periodísticos han tenido una evolución diferente de acuerdo a la dinámica de la pandemia, con muchos textos interpretativos al inicio, de opinión en la parte central, e informativos al final.

Por otra parte, si bien en situaciones de crisis sanitarias, los comunicadores y los sanitarios comparten una "relación de simbiosis"23, 25, nuestros datos indican que los científicos y los profesionales sanitarios han tenido un papel limitado en la elaboración de la información sobre la pandemia, en la que las institucionales han sido la principal fuente de información. Presumiblemente, la orientación del diario justifica esta distribución. Sin embargo, sí que se han detectado informaciones sobre salud pública, gestión sanitaria y sobre medicamentos. Si bien 


\section{LA CRISIS DEL CORONAVIRUS VISTA DESDE UN DIARIO DE DIFUSIÓN NACIONAL. \\ EVOLUCIÓN ENERO-JUNIO DE 2020}

BEGoÑA CANTABRANA; NATALIA COBIÁN; CLAUDIO HIDALGO-CANTABRANA; AGUSTÍN HIDALGO

el número ha sido muy inferior al dedicado a las repercusiones de la pandemia en la economía o en cualquiera otro ámbito, sí que han tenido la calidad y la frecuencia para contribuir a una información eficaz, complementaria a la aportada por otros medios, para formarse una idea global de los problemas de índole sanitario que ha provocado la pandemia. De hecho, los aspectos dedicados a la autoprotección, evitación de contagios y observación de medidas sociales se han mantenido de forma recurrente.

Los titulares de los textos periodísticos han sido neutrales, aunque en alguno de ellos puede identificarse expresiones no aconsejadas que pueden herir la sensibilidad de algún pueblo y/o de sus habitantes. Es el caso del titular "El nuevo virus chino se contagia entre humanos" del artículo de Jaime Santirso del 20 de enero. La expresión virus chino se considera inadecuada porque, aunque tentativamente se pretenda aludir al origen de la infección, atribuye una responsabilidad e imputabilidad al pueblo chino en la génesis del virus, lo que es inexacto y puede estigmatizar a los ciudadanos chinos. Esta es una de las razones, las otras son de índole científico y de normalización de la denominación, por las que la OMS se apresura a dar nombre oficial a las epidemias lo antes posible. En el interior del artículo, el periodista alude al coronavirus de Wuhan, expresión que tampoco es afortunada.

En los textos periodísticos se han utilizado medios gráficos de forma importante. Como han señalado algunos autores ${ }^{26}$ "Los datos numéricos han sido el recurso informativo más valioso y las infografías los contenidos multimedia más desarrollados". A este respecto, las imágenes con personas que portan mascarillas, de hospitales de campaña, de la medicalización del recinto ferial IFEMA, de la instalación de estaciones de triaje extra-hospitalario, del palacio de hielo habilitado como morgue, de las funerarias saturadas o del ejercito retirando cadáveres de las residencias de ancianos, ilustran adecuadamente la dimensión y gravedad de la pandemia.

Nuestro trabajo también ha permitido poner de manifiesto la ausencia de un anuncio temprano de la gravedad potencial de la situación tanto en la Unión Europea como en España. De haberse producido, podría haberse adelantado la adopción de medidas preventivas y haber comprometido la implicación de la ciudadanía y de las fuerzas sociales en el control de la pandemia. Pero, indudablemente, esto último es incurrir en historicismo. Lo que es indudable es que durante el período que abarca el estudio la crispación política ha alcanzado cotas elevadas hasta el punto de recurrir intencionadamente a la confusión, en la que con frecuencia la ciencia ha sido ideologizada por la política. Por eso, es importante atenerse a los hechos contrastados siguiendo la recomendación de Joaquín Estefanía: "Cuando se olvida la ciencia y empieza la ideología, hay que volver a los hechos" 27 .

\section{REFERENCIAS}

1. Muñoz E. Cultura, ciencia y tecnología de la vida: biotecnología y desarrollo en distintos contextos culturales. En: López-Cerezo JA, Sánchez-Ron JM (Eds.). Ciencia, Tecnología, Sociedad y Cultura en el cambio de siglo. Madrid: Biblioteca Nueva; 2001. p. 41-54.

2. Sánchez-Ron JM. El siglo de la ciencia. Madrid: Taurus; 2000.

3. Venter JC. La vida a la velocidad de la luz. Desde la doble hélice a los albores de la vida digital. Barcelona: crítica; 2013.

4. González García M, Cantabrana B, Hidalgo A. Ciencia, medicina y medicamentos. Un estudio del periodo 2001-2016. FEM. 2020; 23(1):17-24

5. Revuelta G. Salud y medios de comunicación en España. Gac Sanit 2006; 20: 203-208.

6. Ronco-López M, Peñafiel C, Echegaray L. El periodismo de salud en España. La información de salud en la prensa española (2000-2010): aproximación a los 


\section{LA CRISIS DEL CORONAVIRUS VISTA DESDE UN DIARIO DE DIFUSIÓN NACIONAL. EVOLUCIÓN ENERO-JUNIO DE 2020}

BEGOÑA CANTABRANA; NATALIA COBIÁN; CLAUDIO HIDALGO-CANTABRANA; AGUSTÍN HIDALGO

estudios documentales existentes. Doc Cien Inf 2014; 37: 267-304.

7. Sánchez-Castillo S. Las enfermedades raras en la prensa española: una aproximación empírica desde la teoría del framing. Ámbitos 2013; 22:1-16.

8. Vallano A, Llop-Rius R, Bosch M, Danés-Carreras I. Noticias sobre medicamentos en los suplementos de salud de la prensa española. Med Clin. 2005; 124(19):754-9.

9. Westall D. La obesidad infantil en la prensa española. ESMP. 2011; 17:225-39.

10. Carrasco JM, García M, Navas A, Olza I, Gómez-Baceiredo B, Pujol F, et al. What does the media say about palliativa care? A descriptive study of news coverage in written media in Spain. PLoS ONE 2017; 12: e0184806.

11. Laspra B, Muñoz E. Culturas científicas e innovadoras. Progreso social. Buenos Aires: Eudeba; 2014.

12. Murillo Rosado M. El incierto papel de los medios de comunicación en el nuevo contrato social del postcoronavirus. En Calvo JR, Kindelán C, Calvo Ma A (Eds.) La gran pausa. Gramática de una pandemia. Barcelona: Malpaso; 2020. p. 137-148.

13. Polino C. La ciencia en las noticias de América Latina. Una aproximación empírica para el caso de la salud. En López Cerezo JA, Gómez J (Eds.) Apropiación social de la ciencia. Madrid: Biblioteca Nueva; 2008. p. 169-190.

14. Laspra B, Muñoz E. Culturas científicas e innovadoras. Progreso social. Buenos Aires: Eudeba, 2014.

15. Lopera E. Entre conversos, escépticos y negacionistas: cómo abordar el análisis de la cobertura informativa de la ciencia del clima. En Díaz García I, Muñoz van den Eynde A (Eds). Participación y cultura científica en contexto internacional. Madrid: Consejo Superior de Investigaciones Científicas / Catarata; 2011.
16. Camacho-Markina I. La "gripe A", en la prensa española. RLCS. 2009; 64:827-43.

17. Elías C. Formatos mediáticos de la información científica: prensa, periódicos digitales, radio y televisión. En: Elías C. Fundamentos del periodismo científico y divulgación mediática. Madrid: Alianza Editorial; 2008. p. 187-231.

18. Güell O. Los hospitales ultiman planes de contingencia y revisan los protocolos en España. El País. 22 de febrero de 2020.

19. Sánchez Bayle M. Los medios, la epidemia y el miedo. El País. 11 de marzo de 2020.

20. Sevillano EG. Cada país cuenta los muertos a su manera y ninguno lo hace bien. El País. 30 de marzo de 2020.

21. Izquierdo P. El coronavirus empuja a la ciencia a compartir estudios. El País. 5 de febrero de 2020.

22. Vallespín F. Hay que combatir el miedo al futuro. El País. Suplemento Ideas. 19 de enero de 2020.

23. Lázaro-Rodríguez $P$, Herrera-Viedma E. Noticias sobre covid-19 y 2019-n-CoV en medios de comunicación de España: el papel de los medios digitales en tiempo se confinamiento. El Profesional de la Información. 2020; 29, e290302.

24. González-García M, Cantabrana-Plaza B, Hidalgo-Balsera A. Propuestas formativas para estudiantes de ciencias de la salud mediante textos periodísticos. Arch Med (Manizales) 2020; 20:88-99.

25. Lubens P. Journalists and public health professionals: challenges of a symbiotic relationship. Dis Med Public Health Prep. 2015; 9(1): 59-63.

26. Costa- Sánchez C, López-García X. Comunicación y crisis del coronavirus en España. Primeras lecciones. El Profesional de la Información. 2020; 29(3), e290304.

27. Estefanía J. El coste de las malas ideas. El País. 2 de febrero de 2020. 


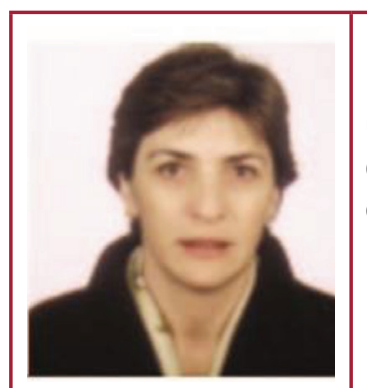

Begoña Cantabrana Plaza es Licenciada y Doctora en Medicina por la Universidad de Oviedo y Profesora Titular de Farmacología en la misma universidad. Su actividad científica se centra en la farmacología hormonal y dedica atención preferente a diferentes aspectos de la innovación docente en los Grados de Medicina y Enfermería.

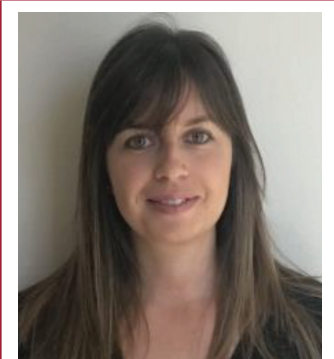

Natalia Cobián Fernández, licenciada en Biología y Máster en Biotecnología Alimentaria por la Universidad de Oviedo, inició su carrera profesional en la industria en el área de microbiología desarrollando tecnologías para la detección de patógenos en aguas de consumo. Posteriormente ha continuado su carrera científica en Estados Unidos donde actualmente trabaja en probióticos y sistemas CRISPR-Cas para edición genética, en North Carolina State University (Universidad Estatal de Carolina del Norte).

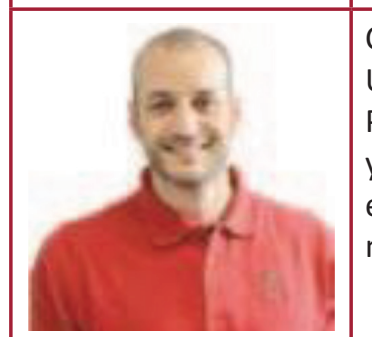

Claudio Hidalgo Cantabrana es Licenciado y Doctor en Biología por la Universidad de Oviedo. Desarrolló su trabajo científico en el Instituto de Productos Lácteos de Asturias (IPLA-CSIC) en el campo de la microbiología y genética asociado a salud humana y actualmente trabaja como científico en la North Carolina State University (Raleigh, US) en el ámbito de la tecnología CRISPR-Cas.

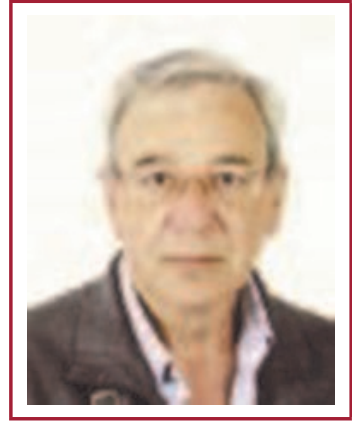

Agustín Hidalgo Balsera es licenciado y doctor en medicina por la Universidad Complutense de Madrid y Profesor de Farmacología de la Universidad de Oviedo. Entre sus áreas de interés se encuentra la repercusión social de los medicamentos y la representación social de la medicina y la enfermedad a través de las manifestaciones artísticas y los medios de divulgación científica y comunicación social. 